\title{
INTERNATIONAL COLLABORATION AND FREEDOM OF SCIENCE*
}

\section{By Sir Henry Dale, C.B.E., F.R.S.}

$\mathrm{A}^{\mathrm{s}}$ $\mathrm{S}$ we come to the end of another year we can see, as yet, no prospect for science of escape from the urgent preoccupation with the means of waging war. On the contrary, with the Union of Soviet Russia now locked in a supreme struggle for its own existence and the world's freedom, and with the United States of America rapidly directing its tremendous scientific and technical potential to the support of the same great cause, the diversion of science from its normal uses and objectives has spread right round the world. Yet even this grim necessity has brought with it some measure of compensation, in drawing closer the bonds of friendship between the men of science in the countries thus united in a common purpose. We in Great Britain received a tremendous encouragement, in the early months of this year, from the visit of President J. B. Conant and his associates to establish in London an office for the maintenance of regular and intimate co-operation between the war researches of our American colleagues and those which are here in hand. More recently, and in spite of all difficulties of communication, the sense of a common peril and a common determination is bringing us into a new and growing intimacy of collaboration with our colleagues of Soviet Russia. The organization of the science of the British Empire for war has brought to London already a number of distinguished colleagues from the Overseas Dominions, and we have heard of others who are on the way. It has been a particular pleasure to gather them here, in the house of the Royal Society, and to invite them to regard it as a centre and a rallying point for discussion of the means by which this new and closer collabor. ation, arising under the stimulus and the necessity of war, may be perpetuated and strengthened for the purposes of peace.

Generous gifts to the Society, during the year, from sister societies in America, have given further welcome evidence of the determination of our colleagues there to come to the help of British science in this time of need. The American Philosophical Society, founded in $\mathbf{1 7 4 3}$ by Benjamin Franklin, with the Royal Society as his model, sent us ten thousand dollars "for the aid of science in Britain". They have confirmed our interpretation of their fraternal gift as betokening a desire to help us to preserve some measure of normal scientific activity in Great Britain during the War, and

* From the presidential address to the Royal Society, delivered on December 1. to keep alive the tradition of a free pursuit of knowledge for the benefit of all men. We have been able to find good use already for a large part of this benefaction, in the maintenance of a number of important researches, which war conditions had threatened to interrupt or to bring to an end. The American Physiological Society similarly sent the Royal Society five thousand dollars as a spontaneous contribution to the support of scientific publication in Great Britain, mentioning physiology as the subject to which they, as physiologists, desired us to give the first consideration. The Rockefeller Foundation, that truly international benefactor and promoter of natural knowledge, had already asked the Royal Society to be responsible for the distribution of twelve thousand five hundred dollars in aid of scientific publication in Great Britain in these difficult times.

Gifts such as these, welcome for their own intrinsic value and for the practical uses which we are readily finding for them, are even more welcome on account of the evidence that they bring of the feeling of comradeship between our American colleagues and ourselves. We can do no less, I think, than assure them of our determination that this closer sense of unity in aims and ideals, with them as with our fellow-citizens of the British Overseas Dominions, shall not be lost, but rather strengthened, when we face together the new problems which the end of the War will bring.

Though the first and imperative call on the science of all free countries is for the means of winning the war, to save the freedom without which science cannot in any true sense survive, we cannot put aside the duty of preparing for the part which science must play in rebuilding and maintaining civilization when peace returns. The Conference recently organized by the British Association on "Science and World Order" attracted more attention from the Press and the public than is usually given to scientific events and discussions ; and it was, indeed, an impressive and significant fact that men of science from a dozen or more different countries, some far distant, should have found it possible now to meet, here in our war-scarred London, and to find the time and the impulse for such debate. We may offer our very sincere congratulations on the success of such an enterprise.

Many who took part in these meetings, held at a time when science finds itself conscript and organized as never before for the destructive pur- 
poses of war, were clearly ready to support the view that it should be as fully organized by the Governments of a world at peace, for its proper purposes of enriching life and enlarging the opportunities of happiness for all men alike. There were not wanting voices, however, such as that of our Biological Secretary, to sound a warning of dangers which might be entailed by such fullness of association between science and government as others were advocating with conviction and enthusiasm. Freedom and opportunity, it was pointed out, rather than organization, provide the conditions for the highest types of research, and thus, in the end, for the greatest services which science can give to mankind. I find myself in sympathy with this view, and nobody here, I think, would suggest that it is usually possible to organize the researches which advance boldly into the unknown, and open new vistas to human understanding. Here we shall certainly not overlook the fact that, in the period between the two wars, important funds have been placed at the disposal of the Royal Society by a series of generous benefactors, to be administered for the support of researches over a wide range of subjects, in complete independence of any control by the State.

On the other hand, I think that it will be agreed that the remarkable development in Great Britain, since 1914, of the State support of research administered by the three Advisory Councils-the Department of Scientific and Industrial Research, the Medical Research Council and the Agricultural Research Council-normally in relation to the needs and the activities of a nation at peace, has taken place without any obvious detriment or danger to the freedom of science. The Royal Society's former function, of advising the Government directly on all scientific matters, and of organizing such systematic researches as were then undertaken in the public interest, has, of necessity, been shared and greatly diminished. We, as a Society, however, can fairly regard this development as, in many respects, a realization of the plans and the dreams of our predecessors here; and I do not think it fanciful to claim that our Society's traditions and standards have been still effective, through the influence of our fellows on the Advisory Councils and their Committees, and through the filling of their chief executive offices by men of our fellowship. As a whole-time research worker myself, since 1914, under the body which became the Medical Research Council, and the senior now in that service, I can bear grateful witness to the freedom of opportunity which can exist under an enlightened organization and control, exercised on behalf of the Government. I have no reason to suppose that the conditions are otherwise under the other Research Councils. Nor should we lose sight of the fact that a further large proportion of the free research of the country is now indebted to support from the State through grants to the universities, administered without any trace of detailed Government control.

While, therefore, the existing mechanisms for the support of science by the State are doubtless susceptible of improvement at one point or another, I find no reason to fear any threat to the freedom of science from them, or from any natural development on those lines. Nor do I fear it from a wider use of the organized application of science and scientific method to problems of public welfare ; nor, again, from a more effective access of scientific knowledge to those responsible for government. A year ago Sir William Bragg told the Royal Society of the formation of the Scientific Advisory Committee to the War Cabinet, under the chairmanship of Lord Hankey, with the President and two Secretaries of the Royal Society as members ex officio. The representation of the Society has, indeed, been strengthened since then, and in a manner most welcome, by the fact that, though I have succeeded him ex officio, Sir William Bragg still gives his wisdom and experience to the work of that Committee, as an extra member.

There is one direction, however, in which I do find some reason to fear for the freedom of science. If science should become entangled in controversial politics, through the over-eagerness of its advocates and champions to invoke the sanction of science, or to claim its potentialities, in support of any special political doctrine, then indeed I believe that the threat to its freedom might become a real danger. Let there be no misunderstanding of my meaning. I am not abusing the privilege of this chair by using 'controversial' as an epithet to be applied to political opinions which I do not happen to share. I see danger if the name of science, or the very cause of its freedom, should become involved as a battle cry in a campaign on behalf of any political system, whether its opponents would describe it as revolutionary or reactionary. If science were allowed thus to be used as a weapon of political pressure, it would be impossible to protect science itself eventually from the pressure of sectional politics. If that should happen the dangers are, I believe, beyond dispute--the danger, for example, that fundamental researches, having no immediately practical appeal, would be allowed to fall into arrears through relative neglect; or the danger that the rigid standards of true science would be relaxed, by allowing the convenience of results for policy or for propaganda to enter into the assessment of their validity as evidence. 
The Royal Society, with its firm and unbroken tradition of complete aloofness from political controversy, may still find it an important part of its function to keep watch and, if necessary, to stand without compromise for the right and the duty of science to seek the truth for its own sake, in complete freedom from any kind of extraneous influence. I hope, indeed, that there will never be need thus to invoke our tradition, in order to protect the freedom and the integrity of science from the enthusiasm and the advocacy of any of its friends.

\title{
PHYSICAL CONCEPTS OF THE MESON THEORY OF THE ATOMIC NUCLEUS
}

\author{
By Prof. W. Heitler \\ Dublin Institute for Advanced Studies
}

\begin{abstract}
A SYMPOSIUM was recently held at the Dublin Institute for Advanced Studies, at which the present state of the meson theory was discussed. The present article discusses some of the views expressed, so far as they may be of interest for the general reader. Most of the views put forward in this article-if not generally known -have been discussed in recent years between Dr. H. Fröhlich and myself.
\end{abstract}

There is at the present time a veritable jungle of literature on the meson theory of the nucleus. Quite apart from the sometimes very extensive calculations, there exist at present two or three different meson theories-they differ essentially in the value attributed to the spin of the mesonand each is claimed to have great advantages. This in itself may be sufficient to stress the very preliminary character of the theory. The meson theory is entirely based upon the principles of quantum mechanics and of special relativity. Yet it could scareely be expected that these principles will be sufficient to solve the problem of the elementary particles; something going far beyond relativistic quantum mechanics will be needed for this purpose. Nevertheless, the meson theory has already yielded a number of very valuable results and suggestions which can be considered as safe whatever the future development may be. We may perhaps compare the situation with that obtained by applying Lorentz's classical theory of the electron to an atom, treating the latter as a classical oscillator. The most striking feature, the existence of stationary states, cannot be understood in this way, but a number of other features, such as the absorption and scattering of light, can be understood quite well. Thus we must not expect that the present meson theory can be used to calculate exactly the binding energy of the deuteron, or that it can give any other quantitative results ; but we can expect to obtain a large number of qualitative results and order of magnitude relations. between the fundamental properties of the elementary particles. These properties turn out to be largely independent of the particular form we choose for the theory and can be explained by using general arguments only. (This does not mean that the development of the formalism is superfluous. It has indeed its merits-and very important ones -but a discussion of this lies outside the scope of the present article.)

The meson theory originated from an ingenious idea put forward by Yukawa in 1935. In order to describe the short-range forces prevailing between a proton and neutron, Yukawa introduced a new kind of field, $\varphi$, which was thought to be analogous to, but different in nature from, the electromagnetic field. The short range of these forces requires a modification of the field equations so that the static part of the field is now described by a modified 'Poisson' equation:

$$
\nabla^{2} \varphi+\lambda^{2} \varphi=0
$$

with its singular solution, $\varphi=g e^{-\lambda r} / r$. The range of the forces is approximately $1 / \lambda$. It is an experimental fact that $1 / \lambda$ is of the same order of magnitude as the classical electron radius $e^{2} / m c^{2}$. $g$ is a new universal constant with the dimensions of a charge. It determines the strength of the nuclear field. We derive its value below.

From (1) we can go over to a wave equation describing waves in vacuo:

$$
\nabla^{2} \varphi-\frac{1}{c^{2}} \varphi+\lambda^{2} \varphi=0 .
$$

(2) can also be considered as a relativistic wave equation for a particle, but in contrast to the corresponding equation in Maxwell's theory, it describes the free motion of a particle with a finite rest mass, $\mu=\hbar / c \lambda$. Using the fact that $1 / \lambda \fallingdotseq e^{2} / m c^{2}$ ( $m$ is electron mass), we obtain for the new mass the order of magnitude :

$$
\frac{\mu}{m} \fallingdotseq \frac{\hbar c}{e^{2}}=137
$$

Moreover, it has long been concluded from the 